\title{
CERÁMICA TARTÉSICA CON DECORACIÓN GRABADA. NUEVOS TESTIMONIOS
}

\author{
José Luis ESCACENA ${ }^{l}$ \\ Alicia DEL RÍO \\ Maria de los Angeles LUNA
}

\section{RESUMEN}

Damos a conocer en el presente artículo dos nuevos documentos cerámicos pertenecientes a vasijas tartésicas decoradas con temas geométricos mediante la técnica del grabado. Proceden respectivamente del Berrueco de Medina Sidonia (Cádiz) y del Cerro Mariana, en Las Cabezas de San Juan (Sevilla).

\section{ABSTRACT}

Two new ceramic documents belonging to Tartesic vessels, whose geometric decorative motifs have been made by the engraving technique, are presented in this paper. The first one was found at El Berrueco in Medina Sidonia (Cadiz) and the second one at Cerro Mariana in Las Cabezas de San Juan (Seville).

\section{PALABRAS ClAVE}

Cerámica, Tartessos, Edad del Bronce, Edad del Hierro.

\section{KEY WORDS}

Pottery, Tartessos, Bronze Age, Iron Age.

\section{PROBLEMÁTICA}

La cerámica tartésica con decoración grabada no ha sido objeto aún de un análisis global que aborde sistemáticamente cuál fue su cronología, su tipología vascular, sus

\footnotetext{
${ }^{1}$ Departamento de Prehistoria y Arqueología. Universidad de Sevilla.
} 
motivos ornamentales o su uso más conspicuo. Ha aparecido ya en secuencias estratigráficas relativamente bien fechadas (Blázquez y otros 1970: lám. XXIX, n; 1979: fig. 12:17), pero otras veces forma parte de repertorios documentales descontextualizados, como ocurre en los casos que ahora nos ocupan. En consecuencia, no es nuestra meta fundamental solucionar en este breve trabajo toda esa problemática, sino únicamente dar a conocer dos nuevos testimonios pertenecientes a sendos yacimientos bajoandaluces, para contribuir a un futuro corpus que recopile más documentación y que pueda abordar el estudio de esta especie cerámica desde perspectivas más globalizadoras ${ }^{2}$.

Por la temática geométrica que caracteriza su decoración, y desde luego también por la ubicación estratigráfica de los ejemplares aparecidos en excavaciones metódicas, este tipo de vasijas se atribuye cronológica y culturalmente al mismo mundo que la cerámica tartésica con decoración bruñida y que la pintada al estilo del Carambolo. Pero estos contextos distan mucho de ser conocidos con la precisión cronológica que desearían los especialistas. Así, mientras algún recipiente de cerámica pintada de tipo Carambolo procedente de la comarca sevillana de Los Alcores ha sido llevado hasta el siglo VI a.C. (Aubet 1982: 387), en otras ocasiones se ha querido ver en este repertorio decorativo un «mundo geométrico» preorientalizante paralelo en comportamientos y en datación al del Egeo (Bendala 1977: 191). Dichas posiciones no constituyen hipótesis de trabajo excluyentes y enfrentadas, pero reflejan claramente la problemática cronológica en que todavía el mundo tartésico está sumido cuando se intenta colocar cada cosa en su momento con cierta precisión (Escacena y Belén 1991). Dos publicaciones recientes han venido a añadir nuevos elementos de análisis en todo este asunto, sobre todo al barajar por primera vez para Andalucía occidental una serie relativamente amplia de dataciones radiocarbónicas calibradas (Ruiz-Gálvez 1995; Castro Martínez y otros 1996: 195-209).

Y si lo relativo a las fechas es aún un problema no resuelto, el simbolismo de las decoraciones y el posible uso ritual de estas vasijas representan todavía temas ni siquiera planteados, si bien las piezas en versión pintada procedentes del Carambolo hicieron sospechar a Blanco Freijeiro la posibilidad de que constituyeran los ajuares de un centro de culto ubicado en la parte alta de dicho cabezo (Blanco 1979: 95-96). En algún caso, la asociación de vasos grabados con geometrismos a ajuares funerarios dentro de necrópolis tumulares de época orientalizante, como ocurre en Doña

\footnotetext{
2 La especie cerámica que estudiamos se decoró con la técnica del grabado, arrastrando sobre la superficie del vaso ya cocido un buril de sílex o un fino punzón metálico. En algunas publicaciones se denomina a este procedimiento decorativo incisión, término que para otros autores alude más bien a los motivos elaborados antes de la cocción.
} 
Blanca (Ruiz Mata y Pérez 1989: lám. 3), abre nuevas e interesantes perspectivas en el estudio de esta variedad cerámica; porque, frente a los poblados, los ambientes funerarios proporcionan recipientes completos -y por tanto de formas bien conocidas- y contextos funcionales precisos que pueden sugerir connotaciones rituales e interpretaciones simbólicas hasta ahora olvidadas.

\section{LOS NUEVOS DOCUMENTOS Y SUS LUGARES DE PROCEDENCIA}

Lo que aportamos en este trabajo es el conocimiento de dos fragmentos cerámicos rescatados en hallazgos casuales, y carentes en consecuencia de situación estratigráfica precisa. El más meridional procede del Monte Berrueco de Medina Sidonia, en la provincia de Cádiz; el otro del Cerro Mariana, ubicado en el mismo casco urbano de Las Cabezas de San Juan (Sevilla). Ambos yacimientos cuentan ya con una información arqueológica relativamente abundante, si bien ha sido objeto de mayor atención hasta ahora la documentación rescatada en el primero.

El Berrueco gaditano es un promontorio principalmente calizo ubicado en el término municipal de Medina Sidonia, a medio camino entre esta población y la de Chiclana de la Frontera (fig. 1). El cerro se alza en la fértil campiña que constituye el hinterland de la Bahía de Cádiz, una zona con grandes posibilidades agropecuarias que debieron de ser explotadas ya durante las etapas pre y protohistóricas (Padilla 1991). Así parecen evidenciarlo para el sector ganadero los restos faunísticos estudiados por Estévez y Paz (1985), y para las actividades agrícolas el hallazgo de dientes de hoz de sílex (Escacena y otros 1984: fig. 3) ${ }^{3}$. Respecto a su localización geográfica, es fundamental su posición intermedia entre la región costera y las estribaciones meridionales de la Cordillera Sub-bética, que facilitaría el acceso a unos recursos diversificados. De un lado, los marinos o procedentes de ambientes costeros en general, como la piedra ostionera, de la que están hechos la mayoría de los molinos de vaivén hallados en el lugar (Escacena y De Frutos 1985: 12). Y de otro los que pueden relacionarse con las zonas interiores del Suroeste ibérico, como son algunos útiles realizados en granito (Escacena y otros 1984: 12).

Las actividades arqueológicas llevadas a cabo en el yacimiento durante el verano de 1982 proporcionaron una secuencia estratigráfica que contaba con siete niveles. Dichas capas se consideraron en principio el reflejo de una ocupación ininterrumpida del asentamiento durante toda la Edad del Bronce. Pero hoy se puede defender la

\footnotetext{
${ }^{3}$ Otras piezas similares han sido localizadas en el Cerro de las Madres, inmediato al casco urbano de Medina Sidonia. Agradecemos la información sobre estos materiales aún inéditos a S. Montañés. Sobre el Cerro de las Madres véase además Escacena y otros 1994.
} 
existencia de ciertos vacíos que afectarían fundamentalmente a la fase comprendida entre el Bronce Medio y la etapa tartésica precolonial (Belén y Escacena 1992: 7071; 1995a: 94). La amplitud temporal de la ocupación humana aporta información para el estudio del largo período transcurrido entre el final del Calcolítico y el Hierro Antiguo. Las correcciones propuestas a la primera lectura implican sobre todo la existencia de un hiato entre los estratos IV y V, que supondría la desconexión estratigráfica y cultural de la etapa tartésica con el mundo anterior. El último horizonte aportado por este sondeo arqueológico en el Berrueco abarca los estratos VI y VII, correspondientes a la primera etapa de la colonización fenicia en la zona. A este momento podría corresponder el nuevo documento que ahora presentamos ${ }^{4}$.

Se trata en este caso de un fragmento de cerámica a mano, de color gris oscuro al interior y negro acharolado en la cara externa (fig. 2: 2 y lám. I). Perteneció a un vaso carenado, que en las tipologías al uso sobre la cerámica tartésica se define normalmente como cuenco o cazuela (Pellicer 1987-88: 466; Ruiz Mata 1979: 6). Presenta una pasta depurada, con desgrasantes finos y muy finos. La vasija de la que este trozo formó parte recibió un ligero alisado interno, mientras que se bruñó intensamente la superficie externa, siendo luego cocida en horno reductor, aparentemente a no muy alta temperatura. Se decoró exclusivamente al exterior mediante grabado postcocción, para lo que se usó con toda probabilidad un buril de sílex dada la finura de los trazos. La parte conservada de este recipiente muestra un motivo en aspa realizado con dos fajas cruzadas. Dichas bandas están formadas a su vez por dos rayas que delimitan campos de múltiples líneas paralelas, que originan en el centro un rombo en reserva. A la derecha de este motivo se plasmó tal vez el tema de la doble hacha, si bien lo que hoy conservamos de la vasija no permite reconstruir con más precisión este otro adorno. Ambos símbolos -y otros que pudieron decorar el recipiente- se plasmaron sobre metopas separadas entre sí por barras verticales a modo de triglifos.

El segundo testimonio que ahora reseñamos procede del Cerro Mariana, en la provincia de Sevilla. Hasta lo que hoy podemos saber, este promontorio constituye el núcleo originario de la actual población de Las Cabezas de San Juan, cuyo casco urbano se asienta parcialmente sobre dicha elevación (fig. 1). Algunos autores han identificado este yacimiento con la antigua ciudad de Ugia, citada por Plinio (Nat. Hist. III, 3, 7) (Tovar 1974: 57-58) y por el Itinerario de Antonino (Roldán 1973: 5859; Sillières 1990: 293). Dicho topónimo aparece también en los Vasos de Vicarello como hito en la calzada romana de Gades a Hispalis (Roldán 1973: 154), entre las ciudades de Hasta (Mesas de Hasta, en Jerez de la Frontera) y Orippo (Torre de los

\footnotetext{
${ }^{4}$ Dicho fragmento fue localizado por D. Francisco Jersi, a quien agradecemos la noticia y las facilidades que nos dio para su estudio y publicación.
} 
Herberos, en Dos Hermanas) (Sillières 1990: 293; Corzo 1992: 36). El yacimiento arqueológico está ubicado sobre un cabezo que forma parte de las estribaciones septentrionales de la Sierra de Gibalbín, dominando tierras de campiña y marismas, y cercano a los arroyos Alocaz, Mosquete y Salado. Las posibilidades estratégicas y defensivas del sitio, emplazado en las inmediaciones de la antigua desembocadura del Betis, explicarían su elección como lugar de asentamiento por las antiguas comunidades humanas, tal y como parecen confirmar los abundantes hallazgos rescatados del cerro y sus proximidades (Cano 1980: 13). No obstante, no hay hasta el momento ningún estudio centrado en los primeros momentos de ocupación. por lo que, aun existiendo indicios de la antigüedad de ésta, no es posible hacer una valoración demasiado ajustada del poblamiento en tiempos prehistóricos. Así pues, actualmente hemos de recurrir para la reconstrucción de la historia más antigua de Las Cabezas a una serie de hallazgos en su mayoría casuales, o a noticias transmitidas por estudiosos como Rodrigo Caro (1634: 133) y Francisco de Bruna (1927: 309-310) .

De corresponder a Ugia, se trataría de una ciudad recogida por Ptolomeo entre las turdetanas (Bendala y Corzo 1992: 97). Sin embargo, la identificación de Las Cabezas de San Juan con esta ciudad fue puesta en duda por algunos investigadores, entre ellos por A. Blázquez, quien argumentaba que este nombre antiguo no aparecía en los testimonios de los restos de las calzadas ni en las inscripciones, y concluía afirmando que debía identificarse más con Torres Alocaz, yacimiento cercano a Las Cabezas de San Juan (Blázquez 1913: 427-428). Esta segunda identificación de Ugia ha sido apoyada por algunos epigrafistas (González Fernández 1988: 107-110), mientras paralelamente ubicarían bien en el Cerro Mariana bien en el cercano cortijo de Las Palmillas la antigua ciudad de Conobaria (o Colobona) (González Fernández 1990: 175-178). No obstante, tampoco existe hoy unanimidad sobre esta última propuesta, ya que Conobaria ha sido llevada también al Cerro de las Vacas, yacimiento al sur de Nabrissa y próximo a la localidad gaditana de Trebujena (Caro Bellido 1985) .

Para las etapas pre y protohistóricas de la ciudad asentada sobre el Cerro Mariana las que ahora más nos interesan-, convendría recordar al menos algunas referencias al poblamiento del entorno inmediato. Éste está constatado desde el Neolítico en la cercana Lebrija (Caro Bellido y otros 1986), y desde el Bronce Final en el promontorio de Torrez Alocaz (Oliva y Chasco 1976). Por último, algunas esculturas de tipo ibérico parecen proceder de la falda meridional del propio Cerro Mariana (Chapa 1985: 106 ss.), si bien pueden corresponder a momentos muy tardíos de esta fase histórica.

\footnotetext{
${ }^{5}$ Tomado de Cano 1980: 15 ss.

' Recoge además este autor una amplia bibliografía sobre la ubicación de Conobaria entre Lebrija y Trebujena.
} 
El testimonio de cerámica grabada localizado en este sitio perteneció en su día posiblemente a una cazuela carenada del mismo tipo que la procedente del Berrueco, aunque en este caso el fragmento no ha conservado la arista de carenación ${ }^{7}$. Se trata de nuevo de una vasija fabricada a mano y en horno reductor, de pasta depurada y bruñida tanto al exterior como en un pequeño filete horizontal de la cara interna. También el color de la parte de dentro es aquí gris, mientras que la superficie de fuera consiguió un negro intenso gracias al concienzudo pulimento a que fue sometida antes de la cocción. Los aspectos técnicos de la decoración de este vaso son idénticos a los descritos para la pieza anterior, pero distinto el tema desarrollado. En este caso es más difícil percibir el conjunto de la composición, por lo que nos limitaremos a señalar la frecuencia de triángulos rellenos de líneas paralelas, que forman parte a su vez de otros triángulos mayores o de rombos (fig. 2: 1 y lám. II).

\section{CONTEXTUALIZACIÓN CRONOLÓGICA Y CULTURAL}

La investigación del mundo tartésico está marcada por una serie de incertidumbres cronológicas que afectan especialmente a su etapa inicial, la conocida como fase precolonial. En parte, la responsabilidad de estas oscilaciones recae sobre las imprecisiones para una datación ajustada que ofrecen los materiales cerámicos, sobre todo en la etapa prehistórica de dicha cultura, en la que la producción vascular pudo estar vinculada en gran medida a una elaboración básicamente doméstica como ha propuesto Barceló (1995: 568). Así, cada investigador ha querido ver una cronología más o menos vieja en los testimonios que exhumaba según le parecieran arcaicos o no los rasgos tipológicos del conjunto cerámico, o según éstos continuaran de cerca las antiguas tradiciones cerámicas del Bronce Pleno local o se alejaran de ellas. Con base en tales discrepancias metodológicas, los investigadores se dividen hoy en varios grupos y subgrupos que defienden posiciones enfrentadas a la hora de analizar los orígenes y formación del Bronce Final bajoandaluz. En síntesis, se han propuesto dos hipótesis radicalmente opuestas: la que asume una sustancial continuidad entre las poblaciones tartésicas y las prehistóricas que las precedieron en la zona, al menos desde el Calcolítico, y la que quiere ver una cesura entre unas y otras, de manera que los grupos protohistóricos poco deberían, ni cultural ni étnicamente, a los del tercer y segundo milenios a.C. que habían habitado la región, sino que entre ambas ocupaciones habría que colocar una fase de vacío demográfico en coincidencia cronológica con la clásica Edad Oscura mediterránea ${ }^{8}$.

\footnotetext{
${ }^{7}$ Conocemos este documento a través de D. Antonio Jiménez, a quien agradecemos las facilidades dadas para su estudio.

${ }^{\natural}$ Hemos tratado este problema en profundidad en un trabajo reciente: Escacena 1995.
} 
En coherencia con nuestra vinculación a esta segunda perspectiva, el análisis cronológico que aquí hacemos de las dos piezas estudiadas tiene presente las revisiones estratigráficas asumidas en trabajos recientes que abordan la cronología inicial de los enclaves tartésicos hasta ahora sondeados en sus estratos más bajos (Amores 1995; Belén y Escacena 1992 y 1995a; Escacena y Belén 1991 $)^{9}$. Por tanto, el lector encontrará a veces discrepancias entre la datación defendida aquí para los contextos de los que proceden los paralelos de nuestra cerámica y las fechas sugeridas por los propios excavadores de esos yacimientos de referencia. En este sentido, resulta paradigmático el caso del Carambolo, porque para este enclave se ha planteado una interesante polémica entre quienes defienden su cronología exclusivamente colonial (Amores 1995; Belén y Escacena 1992: 18-19; 1995a: 93; Caro Bellido 1989: 18; Izquierdo y Escacena e.p.) y quienes sostienen la existencia de niveles claramente anteriores a la presencia fenicia en el área del Bajo Guadalquivir (Ruiz Mata 1986: 537 y 549; Aubet 1982: 387). En cualquier caso, el lote de paralelos que a continuación recogemos no pretende ofrecer una relación exhaustiva de todos los testimonios existentes en Andalucía occidental sobre este tipo cerámico. Se trata sólo de recopilar aquellos documentos que ofrecen de alguna forma una datación relativamente precisa.

Por lo que se refiere al contexto cronológico de estos vasos dentro del mundo tartésico, uno de los mejores datos lo proporcionan los fragmentos rescatados en el Cabezo de San Pedro (Huelva). En este sitio se documenta el tipo en la Fase I (Blázquez y otros 1979: 33, fig. 12: 17), fechada por los excavadores entre los siglos IX y VIII a.C., y llevada luego por Blázquez (1992: 250) incluso al X a.C.. Pero su datación podría limitarse a los primeros siglos citados en función del hallazgo en el mismo contexto estratigráfico de materiales cerámicos a torno, sólo ausentes en la fase I-A de dicho sondeo. En cualquier caso, a este momento se atribuyó la construcción de un muro de pilares de factura fenicia (Fernández Jurado 1986: 214; y 1988-89, vol. 1: 81-83; Ruiz Mata y otros 1981: 188).

En El Gandul (Alcalá de Guadaira, Sevilla), la cerámica grabada con motivos geométricos apareció en el estrato VI, fechado en el siglo VII a.C. (Pellicer y Hurtado 1986: 339). En el mismo ambiente se documentaron ánforas fenicias con similar fecha.

También en la provincia de Sevilla, el yacimiento de Montemolín (Marchena) ha proporcionado un fragmento de este tipo en el estrato II (Chaves y De la Bandera

\footnotetext{
${ }^{9}$ De esta lista debe excluirse la revisión de la cronología más antigua de Setefilla llevada a cabo por Martín de la Cruz (1987: 204), ya respondida en otra ocasión (Escacena y Belén 1991: 13-14); igualmente, la corrección de Bendala (1992: 32-33) a la fechas de los enterramientos tumulares de este mismo yacimiento, contestada en Belén y Escacena 1995b: 75
} 
1984: fig. 5.37: z), en un contexto sin cerámica a torno pero datado entre los siglos VIII y VII a.C. (Chaves y De la Bandera 1984: 152-154).

En la costa gaditana, el poblado de Doña Blanca, en El Puerto de Santa María, ha ofrecido, entre otros vasos grabados, un fragmedo decorado con el motivo de doble hacha, muy parecido al nuestro del Berrueco. Dichos testimonios acompañaban en todos los casos a materiales a torno de tipología fenicia (platos de engobe rojo, ampollas, lucernas, etc.), proporcionando en conjunto una datación del siglo VIII a.C. (Ruiz Mata 1986: fig. 3: 37; 4: 14 y 32) ${ }^{10}$. Y en La Cumbres, la necrópolis tumular del asentamiento de Doña Blanca, una urna de incineración llevaba asimismo decoración grabada geométrica en el cuello, en un contexto funerario con una pátera fenicia de barniz rojo de mediados del siglo VIII (enterramiento 58 del túmulo I) (Ruiz Mata y Pérez 1989: 294, fig. 3: pieza central) ${ }^{11}$.

También de la provincia de Cádiz proceden otros testimonios contextualizados. En Vejer de la Frontera, un vaso se decoró con una especie de molinetes que se rellenaron a su vez de almagra. Se localizó en una estructura fechada según los excavadores entre el 750 y el 650 a.C. (Giles y otros 1993-94: 48) ${ }^{12}$.

En Acinipo (Ronda, Málaga), la cerámica tartésica con decoración grabada comienza en los niveles inmediatamente anteriores a la presencia del torno, por lo que han sido llevadas allí hasta el siglo IX a.C. Pero continúa en ambientes plenamente coloniales, en cronologías de hasta la segunda mitad del siglo VII a.C. (Aguayo y otros 1985: 299-302).

De la Corduba prerromana proceden otros hallazgos localizados en niveles sin cerámica a torno (Murillo 1994: 210) ${ }^{13}$. De tal situación estratigráfica se ha desprendido una cronología precolonial. No obstante, la llegada de los productos torneados al Guadalquivir medio debió de producirse en buena lógica algún tiempo después que a la cuenca inferior, por lo que esta asignación cronológica debe de hacerse siempre con relación a tal circunstancia. De hecho, desde el estuario del río hacia el Norte los productos coloniales conocieron ciertas dificultades para penetrar en los primeros momentos de la presencia fenicia (Belén y Escacena 1995b: 79 y 81).

\footnotetext{
${ }^{10}$ De este yacimiento proceden otros muchos testimonios aún inéditos, noticia que agradecemos a su excavador.

${ }^{11}$ En la foto a que aludimos no se observa bien la decoración, pero dicha urna puede verse ya expuesta en el Museo Municipal de El Puerto de Santa María (Cádiz).

${ }^{12}$ De este contexto se obtuvo una datación radiocarbónica a partir de hueso, que dio $2690 \pm 50 \mathrm{BP}$ (no cal.) = 820 BCcal. Véase Giles y otros 1993-94: 45-46.

${ }^{13}$ En esta publicación no se ofrece dibujo de dicha cerámica, y se cita como decoración «esgrafiada».
} 
En conclusión, y por lo que se refiere a la datación de esta especie cerámica, la documentación disponible permite situarla a caballo entre los últimos tiempos de la fase precolonial tartésica y los comienzos del Hierro Antiguo, tal vez con apogeo en el siglo VIII a.C. En cualquier caso, constituiría, junto a los vasos pintados de tipo Carambolo y a los decorados con motivos bruñidos, una expresión más del estilo geométrico que, como a otras culturas mediterráneas, afectó al mundo tartésico inmediatamente antes del fenómeno orientalizante.

Por último, cabe al menos hacer alusión al hecho de que, al menos en el área gaditana, estos vasos han aparecido en contextos funerarios. Tal es el caso del ejemplar ya reseñado procedente de la necrópolis tumular de Las Cumbres, pero también el de un lote hallado entre las tumbas de Asta Regia (González Rodríguez y otros 1995: lám. 2 y foto 2). Sin que falten en contextos habitacionales, esta ubicación en ambientes sagrados sugiere tal vez un alto valor simbólico de dicha especie cerámica en el mundo tartésico.

\section{BIBLIOGRAFÍA}

AMORES, F. (1995): «Las cerámicas pintadas estilo Carambolo: una revisión necesaria de su cronología», Tartessos 25 años después, 1968-1993. Jerez de la Frontera: 159-178.

AGUAYO, P. y otros. (1985): «El yacimiento pre y protohistórico de Acinipo (Ronda, Málaga). Campaña de 1985», Anuario Arqueológico de Andalucía, 1985. II, Actividades Sistemáticas: 294-304. Sevilla, Consejería de Cultura de la Junta de Andalucía.

AUBET, M.E. (1982): «Un vaso a mano con decoración pintada de Los Alcores de Carmona», Trabajos de Prehistoria 39: 385-388.

BARCELÓ, J.A. (1995): «Sociedad y economía en el Bronce Final tartésico», Tartessos 25 años después, 1968-1993. Jerez de la Frontera: 561-589. Ayuntamiento de Jerez de la Frontera.

BELÉN, M. y ESCACENA, J.L. (1992): «Las comunidades prerromanas de Andalucía occidental», en Almagro-Gorbea, M. y Ruiz Zapatero, G. (eds.), Paleoetnología de la Península Ibérica, en Complutum Extra 2-3: 65-87.

--- (1995a): «Acerca del Horizonte de la Ría de Huelva. Consideraciones sobre el final de la Edad del Bronce en el Sudoeste ibérico», en Ruiz-Gálvez, M. (ed.), Ritos de Paso y Puntos de Paso. La Ría de Huelva en el Mundo del Bronce Final Europeo, en Complutum Extra 5: 85-113. 
--- (1995b): «Interacción cultural fenicios-indígenas en el Bajo Guadalquivir», Arqueólogos, Historiadores y Filólogos. Homenaje a Fernando Gascó, tomo I, en Kolaios. Publicaciones Ocasionales 4: 67-101.

BENDALA, M. (1977): «Notas sobre las estelas decoradas del suroeste y los orígenes de Tartessos», Habis 8: 177-205.

--- (1992): «La problemática de las necrópolis tartésicas», Congreso de Arqueología Ibérica: Las Necrópolis (Madrid, 1991), en Varia 1: 27-36. Madrid, Universidad Autónoma de Madrid.

--- y CORZO, R. (1992): «Etnografía de la Andalucía occidental», en Almagro-Gorbea, M. y Ruiz Zapatero, G. (eds.), Paleoetnología de la Península Ibérica, en Complutum 2-3: 89-99.

BLANCO, A. (1979): Historia de Sevilla. I (1) La Ciudad Antigua (Desde la prehistoria a los visigodos). Sevilla, Universidad de Sevilla.

BLÁZQUEZ, A. (1913): «La vía romana de Cádiz a Sevilla», Boletín de la Real Academia de la Historia LXII: 425-429.

BLÁZQLEZ, J.M. (1992): Fenicios, Griegos y Cartagineses en Occidente. Madrid, Cátedra.

--- y otros (1970): «Las cerámicas del Cabezo de San Pedro», Huelva Arqueológica I.

--- (1979): Excavaciones en el Cabezo de San Pedro (Huelva). Campaña de 1977 (Excavaciones Arqueológicas en España 102). Madrid, Ministerio de Cultura.

BRUNA, F. de (1927): «Noticia y explicación de un monumento antiguo romano descubierto en la villa de Las Cabezas de San Juan del Arzobispado de Sevilla», Memoriae Literariae de la Academia Sevillana, tomo I de Buenas Letras.

CANO, M.L. (1980): Historia de Las Cabezas de San Juan. Las Cabezas de San Juan, Ayuntamiento de Las Cabezas de San Juan.

CARO, R. (1634): Antigvedades, y Principado de la Ilvstrissima Civdad de Sevilla. $Y$ Chorographia de sv Convento Ivridico, o Antigva Chancilleria. Sevilla; Andrés Grande, Impressor de Libros.

CARO BELLIDO, A. (1985): «Conobaria. Contribución al estudio en torno a su localización», Anales de la Universidad de Cádiz II: 7-16.

--- (1989): Cerámica gris a torno tartesia. Cádiz, Universidad de Cádiz.

--- y otros (1986): «Informe sobre la prospección arqueológica con sondeo estratigráfico en el solar de la calle Alcazaba (Lebrija, Sevilla)», Anuario Arqueoló- 
gico de Andalucía 1986. II, Actividades Sistemáticas: 168-174. Sevilla, Consejería de Cultura de la Junta de Andalucía.

CASTRO MARTÍNEZ, P.V. y otros (1996): Cronología de la Prehistoria Reciente de la Península Ibérica y Baleares (c. 2800-900 cal ANE) (BAR Intern. Series 652). Oxford.

CORZO, R. (1992): Las Vias Romanas en Andalucía. Sevilla, Consejería de Obras Públicas y Transportes de la Junta de Andalucía.

CHAPA, T. (1985): La Escultura Ibérica Zoomorfa. Madrid, Ministerio de Cultura.

CHAVES, F. y DE LA BANDERA, M.L. (1984): «Avance sobre el yacimiento arqueológico de Montemolín (Marchena, Sevilla)», Papers in Iberian Archaeology (BAR International Series 193): 141-186. Oxford.

ESCACENA, J.L. (1985): «El «Monte Bernueco» de Medina Sidonia (Cádiz): un modelo de transición del Calcolítico al Bronce en Andalucía occidental», Gades 13: 69-101.

--- (1995): «La etapa precolonial de Tartessos. Reflexiones sobre el «Bronce» que nunca existió», Tartessos 25 años después, 1968-1993. Jerez de la Frontera: 179214. Jerez de la Frontera, Ayuntamiento de Jerez de la Frontera.

--- y BELÉN, M. (1991): «Sobre la cronología del horizonte fundacional de los asentamientos tartésicos», Cuadernos del Suroeste 2: 9-42.

ESCACENA, J.L. y DE FRUTOS, G. (1985): «Estratigrafía de la Edad del Bronce en el Monte Berrueco (Medina Sidonia, Cádiz)», Noticiario Arqueológico Hispánico, 24: 7-90. Madrid, Ministerio de Cultura.

ESCACENA, J.L. y otros (1984): «Avance al estudio del yacimiento del Cerro del Berrueco (Medina Sidonia - Cádiz)», Anales de la Universidad de Cádiz I: 7-32.

--- (1994): «De la fundación de Asido», Spal 3: 179-207.

ESTÉVEZ, J. y PAZ, M.A. (1985): «Análisis faunístico», en Escacena, J.L. y De Frutos, G., «Estratigrafía de la Edad del Bronce en el Monte Berrueco (Medina Sidonia, Cádiz)", Noticiario Arqueológico Hispánico 24: 84-85.

FERNÁNDEZ JURADO, J. (1986): «La influencia fenicia en Huelva», en Del Olmo, G. y Aubet, M.E. (dtres.), Los Fenicios en la Península Ibérica, vol. II: 211-225. Sabadell, Ausa.

--- (1988-89): Tartessos y Huelva, en Huelva Arqueológica X-XI.

GILES, F. y otros (1993-94): «Fechas de radiocarbono 14 para la Prehistoria y Proto- 
historia de la provincia de Cádiz», Boletín del Museo de Cádiz VI: 43-52.

GONZÁLEZ FERNÁNDEZ, J. (1988): Inscripciones romanas y visigodas de Utrera. Sevilla, Caja San Fernando.

--- (1990): Bronces jurídicos romanos de Andalucía. Sevilla, Consejería de Cultura de la Junta de Andalucía.

GONZÁLEZ RODRÍGUEZ, R. y otros (1985): «Mesas de Asta, un centro indígena tartésico en los esteros del Guadalquivir», Tartessos 25 años después, 1968-1993. Jerez de la Frontera: 215-237. Jerez de la Frontera, Ayuntamiento de Jerez de la Frontera.

IZQUIERDO, R. y ESCACENA, J.L. (e.p.): «Sobre El Carambolo: «La Trompeta de Argantonio»», Archivo Español de Arqueología.

MARTÍN DE LA CRUZ, J.C. (1987): El Llanete de los Moros, Montoro, Córdoba (Excavaciones Arqueológicas en España 151). Madrid, Ministerio de Cultura.

MURILLO, J.F. (1994): La Cultura tartésica en el Guadalquivir Medio, en Ariadna 13-14. Palma del Río.

OLIVA, D. y CHASCO, R. (1976): «Una estela funeraria con escudo de escotadura en «U» en la provincia de Sevilla», Trabajos de Prehistoria 33: 387-397.

PADILLA, A. (1991): «Aproximación a la economía de Asido (Medina Sidonia, Cádiz) y su comarca en época orientalizante», Habis 22: 7-17.

PELLICER, M. (1987-88): «La cerámica a mano del Bronce Reciente y del Orientalizante en Andalucía occidental», Habis 18-19: 461-483.

--- y HURTADO, V. (1986): «Excavaciones en la Mesa de El Gandul (Alcalá de Guadaira, Sevilla)», Anuario Arqueológico de Andalucía / 1986. II, Actividades Sistemáticas: 338-341. Sevilla, Consejería de Cultura de la Junta de Andalucía.

ROLDÁN, J.M. (1973): Itineraria Hispana: Fuentes para el Estudio de las Vías Romanas en la Península Ibérica. Valladolid, Universidad de Valladolid.

RUIZ-GÁLVEZ, M. (1995): «Cronología de la Ría de Huelva en el marco del Bronce Final de Europa Occidental», en Ruiz-Gálvez, M. (ed.), Ritos de Paso y Puntos de Paso. La Ría de Huelva en el Mundo del Bronce Final Europeo, en Complutum Extra 5.

RUIZ MATA, D. (1979): «El Bronce Final -fase inicial- en Andalucía occidental. Ensayo para la definición de sus cerámicas", Archivo Español de Arqueología 52: 3-19.

--- (1986): «Aportación al análisis de los inicios de la presencia fenicia en Andalucía sudoccidental, según las excavaciones del Cabezo de San Pedro (Huelva), S. Bartolomé 
(Almonte, Huelva), Castillo de Doña Blanca (Puerto de Santa María, Cádiz) y El Carambolo (Camas, Sevilla). Homenaje a Luis Siret (1934-1984): 537-556. Sevilla, Consejería de Cultura de la Junta de Andalucía.

--- y PÉREZ, C. (1989): «El túmulo 1 de la necrópolis de «Las Cumbres» (Puerto de Santa María, Cádiz)», en Aubet, M.E. (coord.), Tartessos. Arqueología Protohistórica del Bajo Guadalquivir: 287-295. Sabadell, Ausa.

RUIZ MATA, D. y otros (1981): «Excavaciones en el Cabezo de San Pedro (Huelva). Campaña de 1978», Huelva Arqueológica V: 149-316.

SILliÈRES, P. (1990): Les Voies de Communication de L'Hispanie Méridionale. Paris, Diffusion de Boccard.

TOVAR, A. (1974): Iberische Landeskunde (Band 1: Baetica). Baden-Baden. 

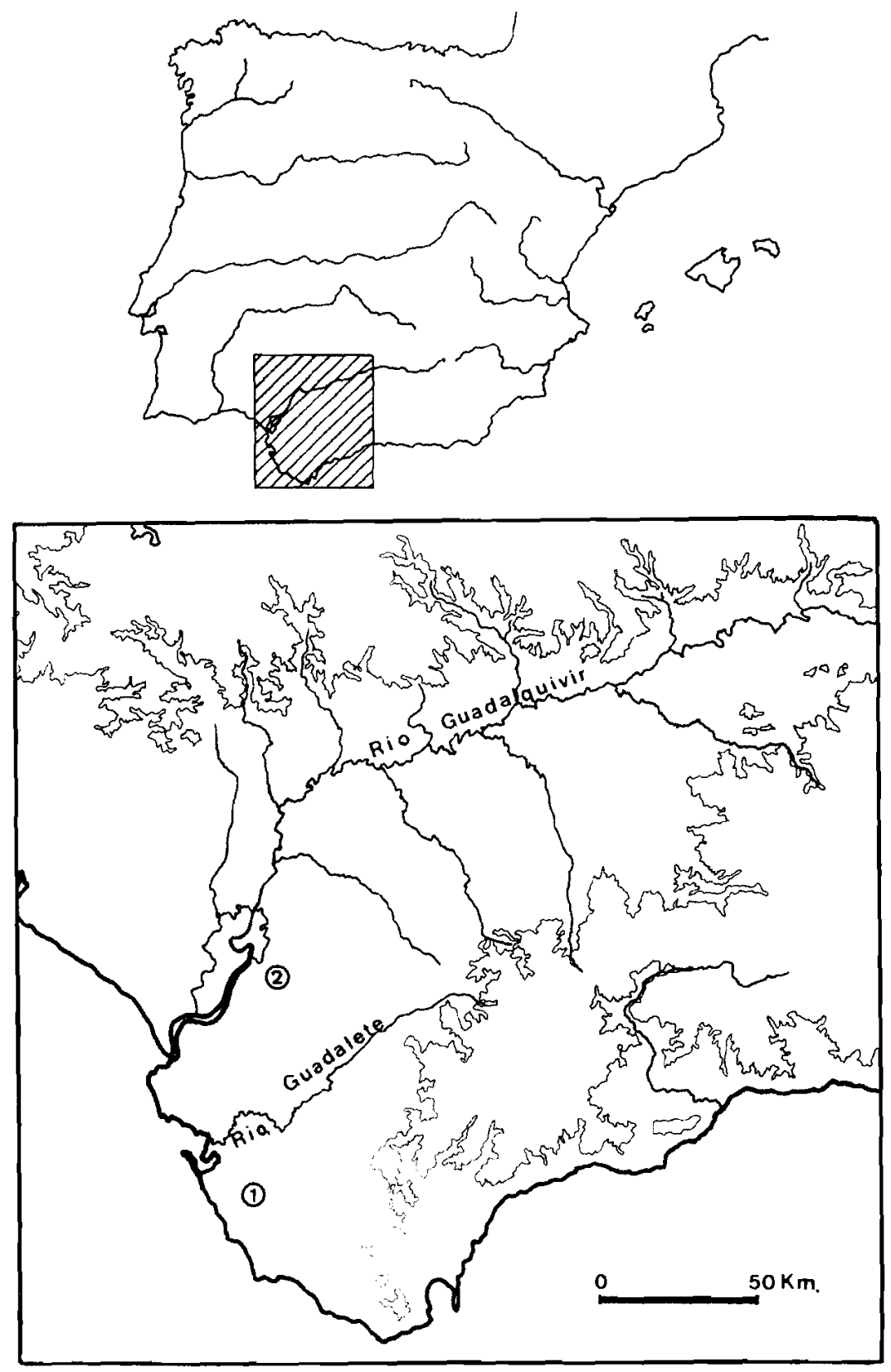

Fig. 1: Localización de la cerámica estudiada: 1) El Berrueco (Medina Sidonia, Cádiz); 2) Cerro Mariana (Las Cabezas de San Juan, Sevilla). 

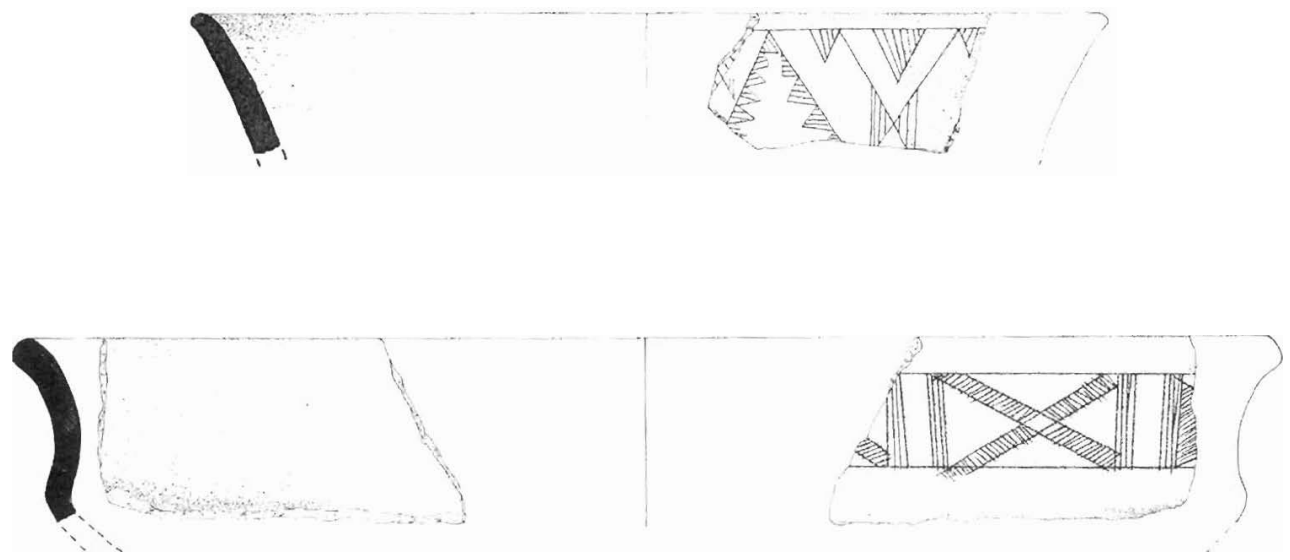

Fig. 2: Cerámica grabada tartésica: 1) Fragmento hallado en El Berrueco; 2) Fragmento del Cerro Mariana.

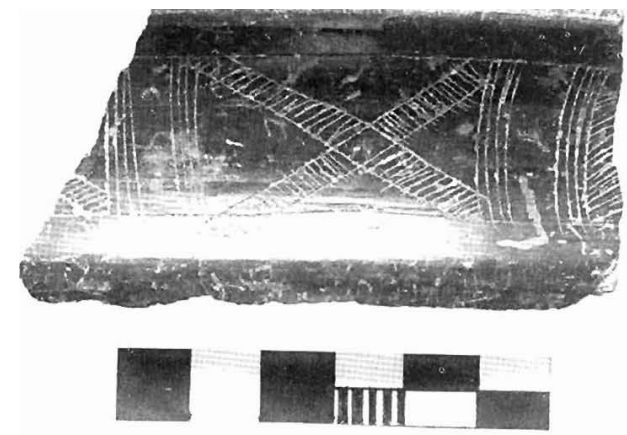

Lám. I: El Berrueco.

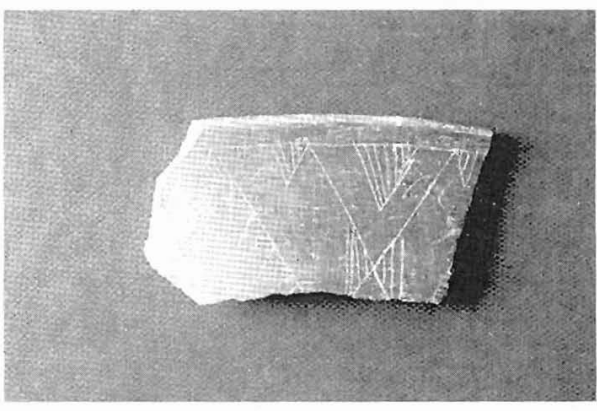

Lám. II: Cerro Mariana. 